\title{
Mécanismes moléculaires de stimulation et désensibilisation de la cellule de Sertoli par l'hormone folliculo-stimulante
}

\author{
V Laurent-Cadoret, F Guillou *
}

INRA/CNRS, URA 1291, station de physiologie de la reproduction des mammifères domestiques PRMD, 37380 Nouzilly, France

(Reçu le 21 novembre 1994 ; accepté le 24 janvier 1995)

\begin{abstract}
Résumé - De nombreuses fonctions sertoliennes sont régulées par l'hormone folliculo-stimulante (FSH). L'interaction de cette hormone avec son récepteur membranaire spécifique conduit à la stimulation de nombreuses étapes intracellulaires incluant l'activation de la protéine $\mathrm{G}$, l'adénylate cyclase et la protéine kinase dépendante de l'AMPc (PKA). Non seulement la FSH présente une action stimulante mais elle est aussi capable de la moduler en induisant progressivement une perte de la capacité de réponse de la cellule : c'est la désensibilisation. En fait, la désensibilisation est dépendante de la concentration de l'hormone et de son temps d'action. Les processus de découplage du récepteur FSH du complexe protéine G/adénylate cyclase à court terme, et l'augmentation des phosphodiestérases, de l'inhibiteur des PKA et la déplétion des récepteurs FSH à plus long terme vont se compléter pour engendrer une désensibilisation des cellules de Sertoli.
\end{abstract}

cellule de Sertoli / stimulation / désensibilisation / hormone folliculo-stimulante

Summary - Stimulation and desensitization of Sertoli cells by follicle-stimulating hormone. Many Sertoli functions are regulated by the receptor-mediated action of follicle-stimulating hormone (FSH). The interaction of FSH with its specific cell surface receptors leads to stimulation of a number of intracellular events, including the activation of guanine nucleotide binding protein ( $G$ protein), adenylate cyclase and the CAMP-dependent protein kinase (PKA) pathway. In addition to positive regulation of cell functions, a phenomenon of refractoriness occurs after primary exposure of target cells to the hormone. Different sites of lesion have been suggested including down-regulation of FSH receptor, uncoupling of the receptor and the G protein/adenylate cyclase complex, and stimulation of nucleotide phosphodiesterases or inhibition of PKA activity. Alterations of cell responsiveness are mediated by a combination of these different mechanisms occurring over different time-scales and hormonal concentrations.

\section{Sertoli cell / stimulation / desensitization / follicle-stimulating hormone}

\footnotetext{
* Correspondance et tirés à part
} 


\section{INTRODUCTION}

Sécrétée par les cellules gonadotropes antéhypophysaires, la FSH régule, conjointement avec la $\mathrm{LH}$, la fonction gamétogène et sécrétoire des gonades. Chez le mâle, le niveau de FSH circulante varie peu et les taux immunoréactifs de FSH circulante dans le plasma de rats immatures est d'environ $100 \mathrm{ng} / \mathrm{ml}$ FSH RP1 (Dohler et Wuttke, 1975). Chez le rat immature, la FSH intervient au niveau testiculaire sur les cellules de Sertoli en stimulant leurs divisions environ jusqu'au $15^{\mathrm{e}}$ jour puis en assurant leurs maturations finales. Essentielle à la formation des jonctions serrées intersertoliennes, la FSH participe à l'établissement de la barrière hémato-testiculaire. Elle est de plus impliquée dans l'initiation de la première vague de la spermatogenèse. D'autre part, la FSH stimule de nombreuses activités biochimiques intrasertoliennes (Griswold, 1993) comme la synthèse d'ADN, d'ARN et de protéines ou la sécrétion de nombreux facteurs notamment des protéines de transport (ABP, transferrine...), des protéases (activateurs du plasminogène...), des hormones et facteurs impliqués dans la prolifération cellulaire (TGF $\beta$, IL...), des métabolites énergétiques (lactate...), des stéroïdes (œstradiol...) ou des composants de la matrice extracellulaire.

La cellule de Sertoli est donc essentiellement sous la dépendance de cette hormone qui, tout en exerçant une action stimulatrice, peut induire progressivement une perte de la capacité de réponse de la cellule selon les conditions physiologiques. Cependant, les mécanismes moléculaires de ce processus de désensibilisation sont encore peu clairs et affectent différents niveaux de la voie de transduction du signal hormonal selon la concentration de l'hormone et son temps d'action.

Les voies transductionnelles de la FSH ont été largement explorées et sont décrites à chaque étape dans cette revue afin de mieux comprendre la régulation de la fonction sertolienne et les mécanismes de désensibilisation (fig 1).

\section{LES ÉTAPES DE TRANSDUCTION DE L'INFORMATION HORMONALE}

Le mécanisme d'action de la FSH met essentiellement en jeu les étapes de transmission suivantes:

- un récepteur membranaire spécifique de la FSH;

- un transducteur : la protéine Gs ;

- un effecteur : I'adénylase-cyclase (AC) ;

- un second messager : l'adénosine monophosphate (AMPc) ;

- une protéine kinase spécifique dépendante de l'AMPc (PKA) ;

- des protéines phosphorylées par la PKA, qui contrôlent les voies métaboliques de la cellule ou l'expression des gènes cibles.

\section{L'hormone folliculo-stimulante, FSH}

La FSH est une gonadotropine qui appartient à la famille des hormones glycoprotéiques. Cette famille est composée de 3 hormones d'origine hypophysaire : I'hormone folliculo-stimulante (FSH), l'hormone lutéinisante (LH) et l'hormone thyréotrope (TSH) et une hormone d'origine placentaire, la choriogonadotropine (CG) existant seulement chez les Primates et les Équidés (Combarnous, 1992). Ces hormones sont formées par l'association non covalente de 2 sousunités $\alpha$ et $\beta$. La sous-unité $\alpha$, commune à toutes ces hormones, est à l'origine de la spécificité d'espèce et la sous-unité $\beta$, différente suivant les hormones, porte essentiellement la spécificité biologique et immunologique de l'hormone. L'association de ces 2 sous-unités est nécessaire pour toute activité hormonale et la structure du dimère 


\section{Stimulations et désensibilisations par la FSH des cellules de Sertoli}

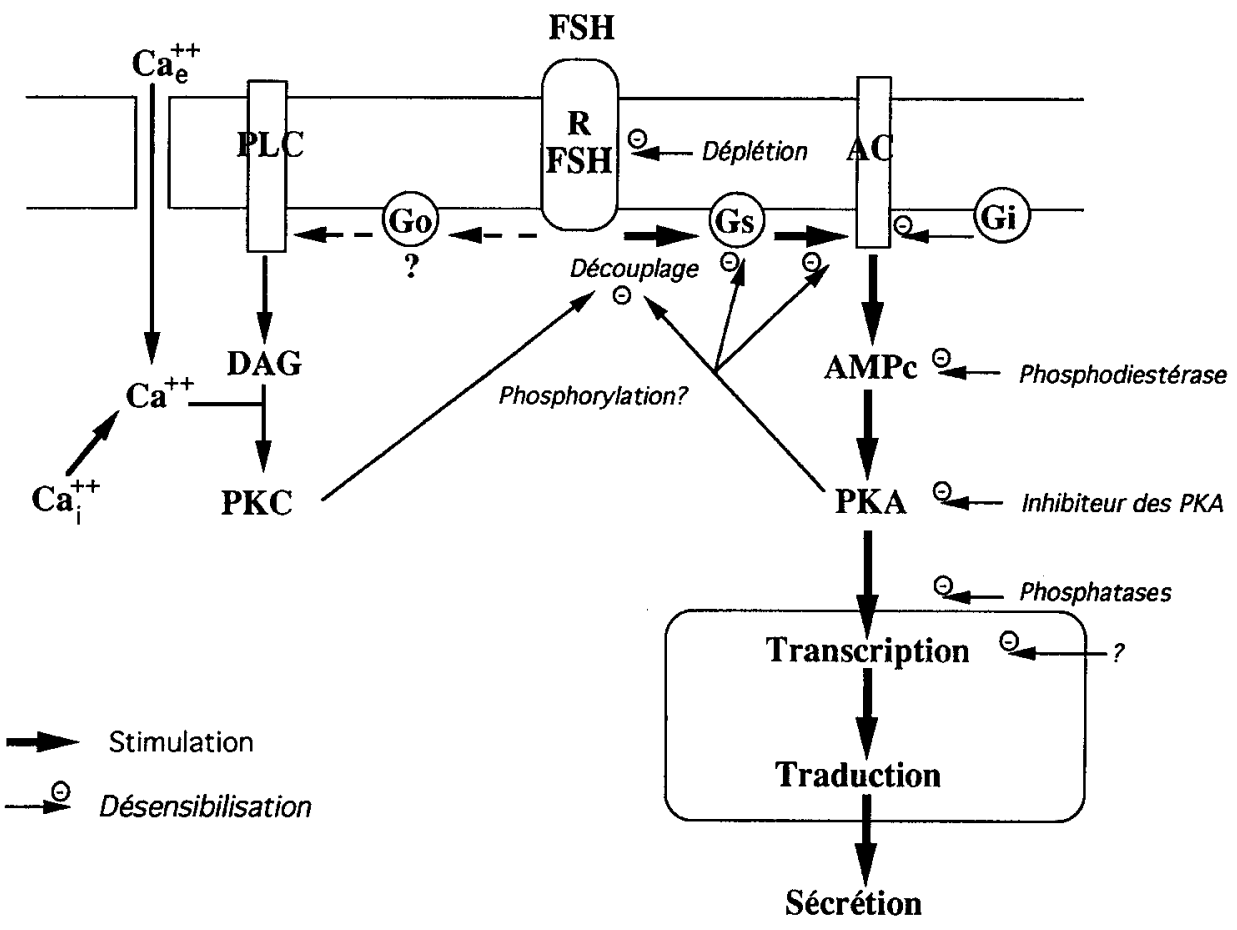

Fig 1. Stimulations et désensibilisations par la FSH des cellules de Sertoli.

ainsi formé porte les informations nécessaires à son maintien dans la circulation sanguine, à la reconnaissance spécifique du récepteur et au déclenchement des réponses biologiques des cellules cibles.

Dans de nombreuses espèces, la séquence en acides aminés de chaque sous-unité de la FSH est parfaitement connue et comprend de 92 à 96 résidus aminés pour la sous-unité $\alpha$ et de 110 à 111 résidus aminés pour la sous-unité $\beta$. Chaque sous-unité est codée par un seul gène. De nombreuses cystéines (10 pour $\alpha$ et 12 pour $\beta$ ) formant des ponts disulfures concourent au maintien de la structure tridimensionnelle de ces hormones. Leur partie polypeptidique est impliquée dans la reconnaissance et la liaison au récepteur. La partie glycannique de ces hormones joue un rôle important dans leur propriétés structurales et fonctionnelles (Combarnous, 1992). Toute déglycosylation de l'hormone entraîne une perte de sa faculté à transmettre le signal par activation de l'adénylate cyclase bien que sa liaison spécifique au récepteur ne soit pas diminuée (Padmanabhan et al, 1991). D'autre part, les résidus distaux des chaînes glycanniques interviennent dans le maintien de l'hormone dans la circulation sanguine (demi-vie de l'hormone), en modifiant leur captation au niveau hépatique et/ou leur élimination par filtration glomérulaire au niveau rénal (Blum et Gupta, 1985). 


\section{Le récepteur FSH}

\section{Structure}

L'étape initiale dans l'action de la FSH sur la cellule de Sertoli est son interaction avec son récepteur membranaire spécifique. La réponse des cellules de Sertoli à la FSH est donc dépendante en premier lieu de l'activité fonctionnelle de son récepteur.

L'analyse de la structure du récepteur FSH est particulièrement difficile du fait du faible nombre de ces récepteurs existant sur les cellules, de leur forte sensibilité à la protéolyse et de leur complexité. L'isolement de son ADNc chez le rat a permis la caractérisation de la structure primaire du récepteur FSH (Sprengel et al, 1990). Il est constitué d'une chaîne polypeptique unique de 675 acides aminés, indiquant un poids moléculaire de $75 \mathrm{kDa}$. Le récepteur $\mathrm{FSH}$ présenterait un motif structural similaire à celui de la superfamille des récepteurs membranaires couplés à la protéine $\mathrm{G}$ (R7G-), comprenant notamment les récepteurs de la $\mathrm{LH}, \beta$-adrénergique, et de la rhodopsine (Strosberg, 1991). Ils sont caractérisés fonctionnellement par leur interaction avec les protéines $G$ et structurellement par une seule chaîne polypeptidique fortement ancrée en son centre dans la membrane plasmique par un motif de 7 segments transmembranaires et exposée en ses extrémités amino-terminale vers l'extérieur et carboxy-terminale vers l'intérieur de la cellule. Par analogie, il a été déterminé 3 domaines pour le récepteur FSH. Un premier domaine amino-terminal hydrophile de 348 résidus est localisé à l'extérieur de la cellule et comprend 3 sites de glycosylation potentiels. Le deuxième domaine de 264 résidus comprend $7 \mathrm{seg}$ ments hydrophobes de 21 à 24 acides aminés intégrés dans la bicouche lipidique de la membrane plasmique sous forme d'hélices $\alpha$. Ces segments transmembranaires sont reliés par de courtes boucles expo- sées à l'extérieur (3) ou l'intérieur (3) de la cellule. Le troisième domaine de 63 acides aminés forme l'extrémité carboxy-terminale cytoplasmique du récepteur.

La comparaison entre les structures primaires du récepteur FSH testiculaire obtenues chez le rat, l'homme et le mouton démontre l'existence d'une très forte homologie de l'ordre de 90\% (Sprengel et al, 1990 ; Kelton et al, 1992 ; Yarney et al, 1993). Tous les résidus cystéines, dont certains seraient nécessaires au maintien de la conformation tridimensionnelle du récepteur, sont conservés, avec une cystéine en position 644 supplémentaire pour le récepteur FSH humain. Trois sites potentiels de $\mathrm{N}$-glycosylation (positions 191, 199, 293) se retrouvent inchangés dans les 3 espèces; un quatrième site (position 318 ) existe sur le récepteur FSH humain. De plus, il existe 5 sites dibasiques de clivage bien conservés (positions 242, 253, 282, 572 et 634), ce qui pourrait expliquer l'obtention de plusieurs sous-unités par les techniques classiques biochimiques lors des premières tentatives de caractérisation du récepteur. Le domaine intracellulaire est très riche en sérines, thréonines qui sont des sites potentiels de phosphorylation.

Un seul gène de structure très complexe code pour le récepteur $\mathrm{FSH}$. II pourrait dériver de la fusion de 2 familles de gènes. II se subdivise en 10 exons et possède une taille minimale de 85 kilobases (Heckert et al, 1992). Les 9 premiers exons codent pour la portion amino-terminale du récepteur. L'exon 1 contient le peptide signal, une zone codant pour une portion spécifique au récepteur $\mathrm{FSH}$ et une première séquence riche en leucines. Les exons 2 à 9 codent pour les séquences répétées riches en leucines. Ces exons dériveraient de gènes codant pour les protéines dites «riches en leucines". Le dernier exon, particulièrement long, code pour une faible portion du domaine amino-terminal, la totalité du 
domaine transmembranaire et l'extrémité carboxy-terminale cytoplasmique du récepteur. II provient probablement d'un même gène ancestral codant pour tous les récepteurs couplés aux protéines $\mathrm{G}$. Le gène du récepteur FSH est localisé sur le chromosome $2 p 21$, très proche du gène codant pour le récepteur LH (Rousseau-Merck et al, 1993).

Le domaine extracellulaire particulièrement long est la caractéristique majeure des récepteurs aux gonadotropines qui les distingue des autres récepteurs couplés aux protéines $G$ (R7G). Leur domaine amino-terminal présente 14 copies imparfaites d'un motif riche en leucines d'environ 20-25 résidus chacun. Ces séquences répétées comportent des zones amphipathiques (prenant une conformation en feuillets $\beta$ ) qui favorisent la formation de surfaces peptidiques prédisposées aux interactions spécifiques protéines/protéines. L'étendue d'un tel domaine, qui est impliqué dans la liaison avec l'hormone, peut s'expliquer par la grande taille et la complexité de la structure hétérodimérique des gonadotropines. Ce domaine conférerait au récepteur ses propriétés de reconnaissance de l'hormone glycoprotéique (affinité et spécificité). Ainsi, il a été identifié dans ce domaine, 2 régions qui constitueraient des sites de reconnaissance de la sous-unité $\alpha$ commune à ces gonadotropines sur leurs récepteurs respectifs. En revanche, une région proche de l'extrémité amino-terminale serait plus spécifique du récepteur et interagirait avec la sous-unité $\beta$ de I'hormone correspondante (Dattatreyamurty et Reichert, 1992). L'ensemble de ces travaux conduit actuellement à 2 hypothèses non exclusives sur l'interaction gonadotropine/récepteur entraînant la transmission du signal hormonal (Braun et al, 1991). Selon la première hypothèse, la liaison de l'hormone à son récepteur induirait un changement conformationnel de l'ensemble du récepteur. Dans la seconde hypothèse, I'hormone se lierait au domaine extracellulaire du récepteur (site à haute affinité de liaison), puis, par un changement conformationnel, l'hormone et/ou une partie du récepteur serait amenées en contact avec le domaine transmembranaire du récepteur (site à faible affinité de liaison), entraînant l'activation de l'adénylatecyclase. Ce modèle suggère l'existence d'un site d'activation du récepteur analogue à la poche de liaison du ligand décrite pour les autres types de récepteurs couplés à la protéine $\mathrm{G}$.

Le domaine transmembranaire des récepteurs aux gonadotropines présente fort peu d'homologie (20 à $25 \%$ ) avec celui des autres R7G (Misrahi et al, 1993 ; Savarese et Fraser, 1992). Cependant, l'importance de ce domaine dans la structure, l'ancrage au niveau membranaire et l'interaction avec la protéine $G$ de ces récepteurs suggèrent que les acides aminés ou même les séquences peptidiques conservés entre eux sont capitaux. On retrouve par exemple, 2 cystéines conservées (Cys 441 et Cys 516 pour R FSH) qui forment dans ces récepteurs un pont disulfure extracellulaire. Ces observations suggèrent un arrangement tridimensionnel similaire au sein de la membrane pour tous les récepteurs de cette famille.

La queue carboxy-terminale localisée dans le cytoplasme est particulièrement différente pour ces récepteurs du fait de sa séquence et de sa taille. Cependant, ce domaine comporte une forte proportion de sérines et thréonines qui sont de nombreux sites potentiels de phosphorylation. L'implication de ces sites de phosphorylation dans le contrôle de l'activité du récepteur, parfaitement démontrée pour les récepteurs $\beta$ adrénergiques (Lefkowitz et al, 1990) et rhodopsine (Wilden et Kühn, 1982), commence seulement a été à être étudiée pour le récepteur LH (Hipkin et al, 1993). Malgré une existence potentielle de ces sites consensus de phosphorylation, leur impli- 
cation n'a pas encore été mise en évidence pour le récepteur FSH.

\section{Expression et régulation des récepteurs FSH}

Chaque cellule de Sertoli comporte un nombre très limité de récepteurs de $\mathrm{FSH}$ qui évolue en fonction de l'âge de l'animal. Chez le rat, le nombre moyen de récepteurs par cellule est d'environ 1600 à 1900 jusqu'à 21 j passant à environ 4000 à $40 \mathrm{j}$ et 7000 à $60 \mathrm{j}$ (Bortolussi et al, 1990). Sur homogénats de tubes séminifères, la constante de dissociation $(\mathrm{Kd})$ est de l'ordre de $6,710^{-10} \mathrm{M}$. Sur membranes tubulaires de rat, 2 types de sites de liaison de l'hormone ont été mis en évidence avec des $\mathrm{Kd}$ de $710^{-11} \mathrm{M}$ et $2,610^{-9} \mathrm{M}$ (Reichert et Dattatreyamurty, 1989).

Des études fonctionnelles sur des sections de tubes séminifères de rats adultes ont montré une modification de la liaison de la FSH ainsi que de la production d'AMPc en fonction des stades du cycle de la spermatogenèse. La liaison de la FSH est 3 fois supérieure aux stades XIII à I par rapport aux stades VI à VII (Kangasniemi et al, 1990a). Le niveau d'AMPc (basal ou stimulé par la FSH) est plus faible aux stades VII-XII par rapport aux stades XIII-I-VI (Kangasniemi et al, 1990b).

L'identification des ARNm du récepteur FSH dans les cellules de Sertoli et la mesure de leur taux d'expression en fonction de l'âge ont été réalisées par Heckert et Griswold (1992). II existe un transcrit majeur du récepteur $\mathrm{FSH}$ de $2,6 \mathrm{~kb}$ et un transcrit mineur de 4,5 kb supposé contenir une extrémité polyA étendue, ce qui indiquerait que les 2 transcrits codent pour la même protéine finale. Ces ARNm sont détectables chez le rat de 10 j et leurs niveaux seraient similaires chez le rat âgé de 20 ou $60 \mathrm{j}$. Au cours du cycle spermatogénétique, le taux des ARNm du récepteur FSH varie suivant les différents stades de différentiation. Ainsi, un contrôle de la réponse induite par $\mathrm{FSH}$ sur les cellules de Sertoli pourrait s'exercer par une régulation du nombre de ses récepteurs par les cellules germinales ou la FSH elle-même.

D'autre part la FSH diminue le taux d'ARNm de son propre récepteur, sans altération de sa transcription. Cette chute posttranscriptionnelle du nombre d'ARNm du récepteur $\mathrm{FSH}$ par l'hormone ne peut être imputable à l'intervention d'une protéine intermédiaire car ce phénomène n'est pas sensible à un inhibiteur de la synthèse protéique. L'hormone exercerait donc un rétrocontrôle sur l'expression de son recépteur via une diminution de la stabilité des ARNm de son récepteur (Themmen et al, 1991).

\section{La voie principale de transmission de l'action de la FSH}

La voie principale de transduction du signal généré suite à l'occupation par la FSH de son récepteur se déroule selon le schéma classique de la voie (AMPC).

\section{Transmission par les protéines G}

Le complexe $\mathrm{FSH} /$ récepteur active l'adénylate cyclase via un transducteur protéique de la famille des protéines $\mathrm{G}$. Ces protéines régulatrices sont des composants clés des systèmes de transmission du signal, relayant l'information des récepteurs membranaires activés par leur ligand vers les effecteurs intracellulaires, tels l'adénylate cyclase (AC), les phospholipases ou les phosphodiestérases ainsi que les canaux potassiques, calciques ou même sodiques (Simon et al, 1991).

II existe une grande variété au sein de la famille des protéines $G$ (plus de 40 connues à ce jour) et une classification selon leur identité dans leur séquence peptidique a été établie. Les plus connues sont les pro- 
téines de type $\mathrm{Gs}(\mathrm{Ns})$ activatrices et $\mathrm{Gi}(\mathrm{Ni})$ inhibitrices de l'adénylate cyclase. Elles répondent à l'activation de récepteurs tels les récepteurs des gonadotropines ou adrénergiques. Les protéines $\mathrm{G}$ sont des protéines hétérotrimériques comprenant les sous-unités $\alpha, \beta$ et $\gamma$ liées de manière non covalente. Les sous-unités $\alpha$ s et $\alpha$ i ont un poids moléculaire apparent de $45-52 \mathrm{kDa}$ et 40-41 kDa respectivement. Les sous-unités $\beta$ et $\gamma$ communes aux différents types de protéines $G$ ont une taille respectivement de $36 \mathrm{kDa}$ et $8 \mathrm{kDa}$. Les protéines $\mathrm{G}$ sont caractérisées par la nature de leur sousunité $\alpha$. C'est en effet la sous-unité $\alpha$ qui est l'élément spécifique de la protéine et qui va déterminer la nature du récepteur et de l'effecteur qu'elle va coupler. Elle comporte aussi la capacité de moduler l'activité de l'effecteur. Les sous-unités $\beta$ et $\gamma$ jouent aussi un rôle au niveau structural comme fonctionnel dans l'hétérotrimère. La sousunité $\gamma$ très hydrophobe présente en son extrémité carboxy-terminale une isoprénylation de la cystéine qui participe à la régulation de la transduction du signal et à l'ancrage dans la membrane de la protéine $G$. Lors de la transmission du signal, le dimère $\beta \gamma$ peut stabiliser l'intéraction des sous-unités $\alpha$ avec les récepteurs et induire ainsi la formation d'une conformation appropriée à l'activation du complexe récepteur/G $\alpha$ mais aussi moduler les effets des sous-unités $\alpha$.

La protéine Gas et 3 formes de protéines Goi $(\alpha i 1,2,3)$ ont été identifiées dans les cellules de Sertoli, les cellules péritubulaires ainsi que dans les spermatocytes pachytènes et spermatides (Paulssen et al, 1991). Leur niveau d'expression varie de manière importante au cours du développement testiculaire (Lamsam-Casalotti et al, 1993). La FSH induit une diminution conséquente des ARNm des protéines Goi1 $(75 \%)$ et Goi2 $(50 \%)$ et une augmentation du niveau des ARNm de la protéine Goi3 (3 fois) (Loganzo et Fletcher, 1992). Cette action de la FSH est due à un mécanisme post-transcriptionnel. En revanche, la FSH ne modifie aucunement le taux des ARNm de Goss.

La protéine Gs est localisée préférentiellement à la périphérie des tubes séminifères, au niveau basal des cellules de Sertoli où sont présents les récepteurs FSH (Dym et al, 1991). Dattatreyamurty et al (1987) ont démontré l'association physique et fonctionnelle des récepteurs FSH avec la protéine Gs. L'interaction entre les surfaces intracytoplasmiques du récepteur et la protéine Gs se réalise via la sous-unité $\alpha$ s. Cependant, les régions de couplage avec la protéine Gs n'ont pas encore été déterminées. Mais les homologies structurales entre le récepteur $\mathrm{FSH}$ et les autres $\mathrm{R} 7 \mathrm{G}$ indiqueraient une similarité de ces domaines clés de la reconnaissance et de la liaison spécifique avec as (Savarese et Fraser, 1992). Une fois le complexe hormone/récepteur formé, la protéine $G$ est activée par fixation du GTP sur la sous-unité $\alpha$ s à la place du GDP. La liaison du GTP entraîne la dissociation des sous-unités, libérant de l'hétérodimère $\beta \gamma$ la sous-unité $\alpha$ s qui va interagir avec l'adénylate-cyclase et l'activer. L'inactivation du système est réalisée grâce à l'activité GTPasique intrinsèque d'os. L'hydrolyse du GTP qui lui est lié en GDP entraîne la réassociation d' $\alpha$ s avec le complexe $\beta \gamma$. La sous-unité $\alpha$ comporte donc, en parallèle de sa capacité d'activation de l'effecteur, l'information pour sa propre inactivation. Ceci permet, d'une part, de réguler le temps d'action de la protéine $G$ sur l'adénylate-cyclase et donc l'intensité du signal transmis et, d'autre part, de réinitialiser le système. L'activation de l'adénylate cyclase par la FSH via la protéine $G$ est donc dépendante du GTP (Fletcher et Reichert, 1986). Or, il existe 2 types de sites de liaison du GTP : I'un à haute affinité et faible capacité de liaison, l'autre à faible affinité et forte capacité de liaison. Zhang et al (1991) ont démontré une action différente du GTP suivant le type de site de liaison 
qu'il occupe. L'occupation des sites de liaison à haute affinité pour le GTP serait essentielle pour l'activation de l'adénylate cyclase alors que les sites de liaison à basse affinité pour le GTP, une fois occupés, réguleraient la liaison de FSH à son récepteur sans être impliqués dans l'activation de l'adénylate cyclase.

Cette première étape intracellulaire de transmission du signal apporté par la FSH présente un niveau d'amplification : en effet, le complexe hormone/récepteur peut stimuler plusieurs protéines Gs.

\section{Activation de l'adénylate-cyclase}

Les protéines $G$, une fois activées par le complexe FSH/récepteur, stimulent l'adénylase-cyclase. La découverte d'une diversité structurale et fonctionnelle des adénylate-cyclases ( 8 types identifiés) suggère un rôle d'intégration du signal à leur niveau (lyengar, 1993).

Les adénylate cyclases sont majoritairement des glycoprotéines membranaires. Elles ont une taille de 110 à $180 \mathrm{kDa}$. L'analyse de leur séquence peptidique a permis d'identifier une structure présentant de grandes homologies avec les transporteurs et canaux ioniques. Elle se présente en 2 domaines de 6 segments transmembranaires reliés par une boucle cytoplasmique. Les extrémités amino- et carboxy-terminales sont cytoplasmiques. Des régions de la boucle cytoplasmique et de la queue carboxy-terminale sont fortement conservées parmi les différents types d'adénylate cyclases et constituent le site catalytique de l'enzyme. L'effet activateur de Gos consisterait en une modification conformationnelle de l'adénylate cyclase: $\alpha s$, une fois liée à cette enzyme, faciliterait l'association fonctionnelle des 2 domaines cytoplasmiques de l'adénylate-cyclase pour former un site catalytique actif. L'adénylate cyclase catalyse la réaction de formation de 3,5'-adénosine monophosphate (AMPC) à partir d'adénosine triphosphate (ATP) avec perte d'un pyrophosphate inorganique (PPi). Ce mécanisme intervient notamment dans l'action de la FSH sur la cellule de Sertoli, I'AMPc ainsi produit constitue le second messager. C'est une nouvelle étape d'amplification du signal extracellulaire car de nombreuses molécules d'AMPc vont être ainsi produites au cours de l'activation de l'adénylate cyclase.

Les ARNm des adénylate cyclases de type 4, 5 et 6 ont été détectés dans le testicule (Gao et Gilman, 1991 ; Premont et al, 1992a). Cependant, la répartition des différents types d'adénylate cyclases dans les cellules testiculaires n'est pas connue.

\section{Production et dégradation de l'AMPC}

L'AMPc, une fois synthétisé par l'adénylate cyclase, se lie et active des protéines kinases spécifiques ou est dégradé par les phosphodiestérases (PDE). Le taux intracellulaire en ce nucléotide cyclique est donc la résultante entre sa synthèse et sa dégradation. L'activation de l'adénylate-cyclase par la FSH va avoir pour conséquence d'élever le taux d'AMPc intracellulaire qui est maximal au bout de 20 min puis revient à son niveau basal après $4 \mathrm{~h}$ de stimulation hormonale (Verhoeven et al, 1980). Le taux d'AMPc n'est pas seulement dépendant de l'activité de l'adénylate cyclase ; il est également contrôlé par les phosphodiestérases qui hydrolysent l'AMPc en 5'AMP. L'intensité du signal transmis par l'AMPc est donc liée à l'activité de cette enzyme de dégradation.

La multiplicité et la diversité tissulaire de ces phosphodiestérases (au moins 25 formes différentes chez les Mammifères) ainsi que leurs propriétés différentes en termes d'affinité pour l'AMPc ou le GMPc, leurs modulations par divers facteurs physiologiques et pharmacologiques et leur cinétique d'hydrolyse ont nécessité l'élaboration d'une classification de ces enzymes. 
Sur la base de leurs caractéristiques structurales et fonctionnelles, les différentes formes de PDE se répartissent en 5 familles (Conti et al, 1991).

Les phosphodiestérases présentes dans les cellules des Mammifères ont une structure commune avec un domaine catalytique bien conservé. Les régions amino- et carboxy-terminales qui encadrent ce domaine catalytique seraient impliquées dans sa régulation et/ou détermineraient la localisation intracellulaire de ces enzymes.

Dans le testicule, 2 familles de PDE ont été mises en évidence les $\mathrm{Ca}^{2+/ C a M-P D E}$ ou PDEl et les PDE spécifiques de l'AMPc ou PDE IV.

Les PDE I ont la propriété d'être activées en présence d'ions calcium par la calmoduline (CaM). Ces enzymes se présentent sous une forme dimérique, chaque sousunité liant une molécule de calmoduline lors de son activation. Différents sous-types ont été identifiés qui se distinguent essentiellement par leur propriété à utiliser l'AMPc ou le GMPc comme substrat préférentiel. Trois formes de ces PDE ont été mises en évidence dans le testicule chez le rat (Geremia et al, 1982).

Les PDE IV sont insensibles aux ions $\mathrm{Ca}^{2+}$ et au GMPc, elles présentent une forte affinité pour l'AMPc. Cette famille de PDE comprend 4 isoformes (PDE1 à 4), codées chacune par un gène différent. Les PDE1 et 2 sont exprimées spécifiquement dans les cellules germinales et les PDE3 et 4 dans les cellules de Sertoli (Swinnen et al, 1989).

Au sein de la cellule de Sertoli chez le rat immature, une régulation positive ou négative par la FSH de l'activité des PDE est observée suivant le type de PDE. À court terme (15-20 min), la FSH produit une inactivation des PDE I (Conti et al, 1991). À plus long terme (1-24 h), la FSH induit une augmentation de l'activité phosphodiestérasique liée aux PDE spécifiques de
I'AMPc. In vitro, cette activation est maximale pour des concentrations de 500 à $1000 \mathrm{ng} / \mathrm{ml}$ en oFSH (Verhoeven et al, 1981). Elle est aussi observée in vivo, indiquant que cette régulation existerait dans les conditions physiologiques (Conti et al, 1983a). La stimulation par la FSH de l'activité phosphodiestérasique est la résultante d'une augmentation de la transcription et de la stabilité des ARNm de ces enzymes (principalement pour la PDE3, x100) (Swinnen et al, 1991) et d'une traduction accrue aboutissant à la néosynthèse des PDE correspondantes (Verhoeven et al, 1981). Ainsi, dans la cellule de Sertoli, I'AMPc régule l'expression de ses propres enzymes de dégradation.

\section{Activation de la protéine kinase dépendante de I'AMPc}

L'étape suivante des effets de la FSH est l'activation par l'AMPc de la protéine kinase cytosolique dépendante de I'AMPc (PKA) et la phosphorylation de substrats protéiques endogènes accompagnée d'une synthèse d'ARNm et de protéines.

Les PKA sont constituées par 2 sousunités régulatrices et 2 sous-unités catalytiques associées de manière non covalente. Deux isoenzymes (types l et II) ont été décrites. Ces isoenzymes diffèrent par leurs sous-unités régulatrices Rl et Rll. Ces sousunités régulatrices présentent chacune 2 isoformes $\alpha$ et $\beta$ : RI $\alpha, \beta$ et RII $\alpha, \beta$ qui sont codées par des gènes distincts. Trois sousunités catalytiques différentes $C \alpha, C \beta$ et $\mathrm{C} \gamma$ ont aussi été identifiées. Malgré une organisation structurale globale assez proche, les sous-unités régulatrices présentent des propriétés différentes en termes de stabilité du dimère, d'antigénicité, de capacité d'autophosphorylation et d'affinité pour l'AMPc et ses analogues, laissant supposer des rôles divergents suivant les conditions physiologiques (Taylor et al, 1992). 
Dans sa forme inactive, la PKA est un tétramère. La sous-unité régulatrice présente alors une forte affinité (>10-9 M) pour la sous-unité catalytique. L'activation de l'enzyme est induite par une augmentation du niveau intracellulaire en AMPc qui se lie avec une forte affinité à 2 sites sur chaque sous-unité régulatrice. Cette liaison provoque une diminution de 4 à 5 ordres de grandeur de l'affinité des sous-unités régulatrices pour les sous-unités catalytiques. II se produit alors une dissociation de l'holoenzyme en une sous-unité régulatrice dimérique et 2 sous-unités catalytiques monomériques, libres et actives. Celles-ci peuvent alors phosphoryler des substrats protéiques endogènes en catalysant le transfert du phosphate $\gamma$ de I'ATP à une sérine ou thréonine de la protéine cible. Lorsque la concentration en AMPc diminue et que I'AMPc lié aux sous-unités régulatrices est libéré, le tétramère R2C2 se reconstitue.

Dans les cellules de Sertoli immatures, l'activité des PKA est maximale (3x) 20 min après l'addition de la FSH. Cette activité se maintient pendant $1 \mathrm{~h}$ puis décroît pour revenir à son niveau de base en $4 \mathrm{~h}$. II existe ainsi une corrélation très étroite entre production d'AMPc et activité des PKA (Means et al, 1974). L'augmentation de l'activité des PKA entraîne, d'une part, des modifications dans la structure ou le fonctionnement de protéines préexistantes dans la cellule et, d'autre part, la synthèse de nouvelles protéines spécifiques via l'activation de l'expression génomique. Ces changements sont dus à la phosphorylation par les PKA de protéines (Ireland et al, 1986) ou d'enzymes clés du métabolisme, ou après migration de la sous-unité activée dans le noyau, à la phosphorylation de facteurs de transcription comme le "cyclic-AMP responsive element binding protein» CREB (Waeber et al, 1991).

Dans le testicule, il existe une répartition spécifique du type cellulaire pour les diffé- rentes sous-unités des PKA (Rl $\alpha$ et $\beta$, RIl $\alpha$ et $\beta, C \alpha$ et $\gamma$ ) et une régulation différentielle de leurs expressions en fonction du développement testiculaire (Landmark et al, 1993). Dans la cellule de Sertoli de rat sont présentes les sous-unités Rl $\alpha$ (49 kDa), $\mathrm{R} I l \alpha(54 \mathrm{kDa})$ et RII $\beta$ (52 kDa) et $\mathrm{C} \alpha(45$ $\mathrm{kDa}$ ). En absence de toute stimulation, les sous-unités régulatrices se répartissent entre $25 \%$ pour RII $\alpha$ et $75 \%$ pour Rl $\alpha$, le niveau de RII $\beta$ étant négligeable (Landmark et al, 1991). L'action de la FSH est préférentiellement médiée par la PKA de type I, bien que la PKA de type II joue un rôle notable dans la transmission de la stimulation (Laurent-Cadoret et al, 1993).

Lors d'une stimulation par la FSH une augmentation très nette du taux des sousunités régulatrices par rapport aux sousunités catalytiques est observée dans les 24 à $48 \mathrm{~h}$ (Landmark et al, 1991). Cependant, l'augmentation du niveau des sous-unités régulatrices est répartie différemment suivant les isoformes. Le niveau des ARNm de RIl $\beta$ augmente de plus de 50 fois alors que le niveau des ARNm des autres sousunités n'est augmenté que de 2 à 4 fois. Cependant, il faut noter que le taux d'ARNm de la sous-unité RII $\beta$, bien que fortement augmenté sous l'action de la FSH, reste négligeable par rapport au niveau des ARNm codant pour les sous-unités Rl $\alpha$ et RIl $\alpha$. Dans les cellules stimulées, la sousunité RII $\beta$ reste donc toujours minoritaire, représentant moins de $10 \%$ des sous-unités régulatrices. Le rôle de cette sous-unité RII $\beta$ dans l'action de la FSH est pour l'instant inconnu. Cette régulation différentielle des ARNm résulte d'une modulation différente tant au niveau transcriptionnel qu'au niveau de la stabilité des messagers (Knutsen et al, 1991). Elle se traduit finalement par une augmentation des isozymes correspondantes. Étant donné qu'il existe une expression différentielle de ces isoenzymes en fonction de l'âge ou des conditions physiologiques, nous pouvons avancer l'hypo- 
thèse que ces isoenzymes pourraient être activées sélectivement et avoir des fonctions distinctes au sein de la cellule de Sertoli.

\section{Les autres voies de transmission de l'action de la FSH}

Alors que l'association de l'action de la FSH avec la voie de l'AMPc est parfaitement bien établie, le rôle des autres voies de transmission de l'information (les phosphoinositides, les PKC et le calcium) qui peuvent intervenir plus ou moins directement dans le mécanisme d'action de la FSH est en revanche nettement moins défini.

\section{La voie des phosphoinositides}

La relation existant entre la FSH et la voie des phosphoinositides dans la cellule de Sertoli est peu étudiée. Cet autre système de transduction du signal existe cependant au sein de la cellule de Sertoli. L'étude de cette voie et de ses interactions potentielles avec celle activée par la FSH est donc importante pour mieux cerner les modulations possibles de l'action de la FSH au sein des cellules de Sertoli.

Cette voie de transduction du signal en réponse à une stimulation cellulaire consiste en l'activation, via un récepteur et une protéine $\mathrm{G}$, d'un effecteur, la phospholipase $\mathrm{C}$ (PLC). La PLC activée hydrolyse le phosphatidylinositol 4,5-biphosphate (PIP2) et produit 2 seconds messagers : l'inositol $1,4,5$, triphosphate (IP3), qui va mobiliser les stocks de calcium intracellulaires, et le 1,2 diacyl-glycerol (DAG), qui, avec le calcium, va activer la PKC. Cette enzyme phosphoryle différents substrats protéiques intracellulaires (Farese, 1984). L'inactivation du processus de transmission du signal est liée à l'activité GTPasique de la sous-unité $\alpha$ de la protéine $\mathrm{G}$. Les seconds messagers sont dégradés et les métabolites ainsi produits participent au cycle de reconstitution du stock de PIP2 membranaire, substrat de la PLC. La voie de transmission du signal par activation des PLC est fonctionnelle dans les cellules de Sertoli. Elle est activée par stimulation de protéines $\mathrm{G}$ spécifiques et modulée par les protéines $\mathrm{Gi}$ mais ne semble pas affectée par la FSH (Quirk et Reichert, 1988). Toutefois, bien qu'aucun effet direct de la FSH sur le métabolisme des phosphoinositides n'ait pu être mis en évidence, cette hormone exercerait un effet inhibiteur sur l'accumulation de leurs métabolites obtenue par l'addition de facteurs dérivés du sérum (Monaco et al, 1988a). Cet effet inhibiteur de la FSH est mimé par tout activateur de la voie AMPc et passerait donc par la stimulation des PKA. Le point d'impact de cette inhibition concerne l'étape de synthèse de l'IP3 et impliquerait soit une inactivation de la PLC, soit une activation des kinases des phospholipides (Monaco et Conti, 1987).

La protéine kinase $\mathrm{C}$ est donc l'enzyme centrale de la voie des phosphoinositides. Cette enzyme est une sérine/thréonine kinase comme la PKA mais les séquences consensus de phosphorylation des substrats par la PKC sont généralement différentes des sites de phosphorylation cibles de la PKA. Neuf isoformes différentes de PKC ont été identifiées jusqu'à présent et regroupées en 2 familles sur la base de leurs structures et de leurs capacités à être régulées par le calcium (Hugh et Sarre, 1993). La première famille comprend les isoformes $\alpha$, $\beta 1, \beta 2, \gamma$, dépendantes du calcium. La seconde famille est constituée par les isoformes $\delta, \varepsilon, \zeta, v$ et $\tau$, indépendantes du calcium. L'activité de la PKC est modulée par le DAG et le $\mathrm{Ca}^{2+}$ libéré des stocks intracellulaires par I'IP3. La liaison du calcium à la PKC induit la translocation de l'enzyme jusqu'à la membrane, plasmique. Le DAG et un cofacteur, la phosphatidylsérine, présents dans la membrane, activent la PKC, 
permettant le transfert du groupement phosphate $\gamma$ de l'ATP sur l'hydroxyle de la sérine ou thréonine de la protéine cible.

Chez le rat, la majorité de l'activité PKC testiculaire est d'origine tubulaire (Nikula et $a l, 1987)$ et a été caractérisée comme provenant de PKC de type $\alpha$ pour les cellules de Sertoli et de types $\alpha, \beta$ et $\gamma$ pour les cellules de Leydig (Pelosin et al, 1991). Les PKC présentent une distribution intracellulaire cytoplasmique, membranaire ou nucléaire et il existe une translocation variable de ces enzymes dans la cellule suivant son état d'activité. La forme active des PKC est liée à la membrane et correspond à la fraction particulaire. Dans le testicule, les PKC sont majoritairement sous forme inactive (>70\%) retrouvées dans la fraction soluble (Nikula et al, 1987).

Chez le rat, au cours du développement testiculaire, il existe une excellente corrélation, in vitro, entre l'action de la FSH sur la production d'AMPc et l'activité des PKC (Eskola et al, 1993). La production d'AMPC stimulée par la FSH augmente de 23 fois entre la naissance et l'âge de $10 \mathrm{j}$ puis décline jusqu'à l'âge adulte. Au cours de cette période pré-pubertaire, une augmentation des ARNm codant pour la PKC de type $\alpha$ et un pic d'activité de la fraction particulaire active de la PKC (6 x) sont observés. D'autre part, l'activation de la PKC par des esters de phorbol inhibe la production d'AMPc induite par la FSH. Cet effet est particulièrement significatif à l'âge de $10 \mathrm{j}$ et n'est plus observable chez le rat adulte. Ainsi, au cours du développement testiculaire, des changements radicaux interviennent dans l'action de la FSH et sa régulation par les PKC.

Dans la cellule de Sertoli, l'activation de la protéine kinase $C$ par des esters de phorbol provoque généralement une inhibition de nombreuses fonctions sertoliennes stimulées par la FSH (Monaco et Conti, 1987 ; Eikvar et al, 1993 ; Laurent-Cadoret et al, 1994 a, b). Deux points d'impact de l'action de la PKC sur la transmission du signal FSH ont ainsi été mis en évidence : l'un au niveau du récepteur car l'effet inhibiteur de l'activation de la PKC ne touche que la production d'AMPc induite par FSH et non celle induite par activation de la protéine Gs ou de l'adénylate cyclase ; l'autre en aval de la production d'AMPc car l'activation de la PKC diminue l'accumulation d'œstrogènes et inhibe la sécrétion de l'activateur du plasminogène induite par la FSH ainsi que par activation de la protéine Gs ou de l'adénylate cyclase. Ni les phosphodiestérases, ni les protéines $\mathrm{Gi}$ ne sont impliquées dans ce processus inhibiteur. La PKC donc d'une part entraînerait un découplage du récepteur FSH avec la protéine Gs et d'autre part modifierait certaines activités enzymatiques comme par exemple la PKA ou l'aromatase qui catalyse la synthèse d'œstradiol.

\section{La voie du calcium}

Parallèlement à la production d'AMPc lors de l'action de la $\mathrm{FSH}$, il a été observé un système de transduction du signal qui met en jeu des mouvements dions calcium dans les cellules de Sertoli (Grasso et Reichert, 1993). La concentration en ions calcium dans les cellules de Sertoli non stimulées est d'environ $90 \mathrm{nM}$. La FSH induit une augmentation rapide ( $60 \mathrm{~s}$ ) de la concentration en calcium intracellulaire (de 2 à 3 fois). Cet effet est obtenu à des doses très faibles de FSH (ED50 $=5 \mathrm{ng} / \mathrm{ml}$ ) (Grasso et Reichert, 1990 ; Gorczynska et Handelsman, 1991). Cette phase initiale particulièrement rapide d'augmentation du calcium intracellulaire est suivie d'une phase de maintien de son taux intracellulaire (jusqu'à $20 \mathrm{~min}$ ). Après stimulation par la $\mathrm{FSH}$, une augmentation parallèle du calcium et de la production d'AMPc est observée. Cependant, le lien entre entrée de calcium et activation de la voie $A M P c$ n'est pas clairement démontré. L'hypothèse d'une libération de calcium à partir des stocks intracellulaires via une production d'IP3, consécutivement à l'action de 
la FSH, a été précédement écartée (Quirk et Reichert, 1988). L'augmentation du taux de calcium intracellulaire est due à une entrée de calcium extracellulaire. Sur les cellules de Sertoli en culture, la FSH stimule l'entrée de calcium extracellulaire via des canaux calciques membranaires sensibles ou non aux variations du potentiel de membrane (Grasso et Reichert, 1990 ; Gorczynska et Handelsman, 1991). Les modifications électrophysiologiques induites par la FSH sur les cellules de Sertoli consistent en un phénomène biphasique avec une phase d'hyperpolarisation très courte $(<3 \mathrm{~s})$ suivie d'une phase de dépolarisation prolongée (Wasserman et al, 1992). Ces variations de potentiel pourraient alors provoquer l'ouverture de canaux calcium dépendants du voltage (Joffre et Roche, 1988). De plus, elles seraient liées à des changements dans la perméabilité de la cellule aux ions sodium et potassium.

La possibilité que le récepteur de la FSH, du fait de sa structure transmembranaire, pourrait former un canal permettant le passage des ions calcium a été envisagée par Grasso et Reichert (1990). Néanmoins, Shibata et al (1992) ont réfuté cette hypothèse. Sur des cellules embryonnaires de rein humain (293 F wtl) transfectées et exprimant en grande quantité un récepteur $\mathrm{FSH}$ de rat fonctionnel, aucun courant calcique n'a pu être détecté suite à la stimulation par la FSH de ces cellules.

Conjointement à son effet activateur sur les canaux calciques, la FSH inhibe l'influx des ions calcium dépendant du sodium dans les cellules de Sertoli (Grasso et Reichert, 1993). Ces 2 effets de la FSH sur les mouvements calciques sont en opposition. Le contrôle de l'influx calcique par la FSH via ces 2 mécanismes serait donc un moyen, en régulant le taux approprié en calcium intracellulaire, pour moduler le signal apporté par la FSH aux cellules de Sertoli.

Le calcium est nécessaire pour la liaison optimale de la FSH à son récepteur. Or, une séquence peptidique (1-15) de la sous- unité $\beta$ de la FSH est homologue au site de fixation du calcium sur la calmoduline (Santa Coloma et al, 1992). Cette capacité de l'hormone à lier le calcium est corrélée à sa capacité d'induire l'entrée de cet ion dans les protéoliposomes. Grasso et Reichert (1993) suggèrent donc qu'une autre voie d'entrée du calcium dans les cellules serait reliée à l'internalisation des complexes FSH/récepteurs et la dégradation de l'hormone dans les lysosomes. Cet autre système d'entrée du calcium dans la cellule serait responsable de la seconde phase soutenue d'élévation du taux de calcium.

\section{DÉSENSIBILISATION}

La liaison de l'hormone à son récepteur membranaire déclenche aussi divers événements qui ont comme conséquence de réduire l'intensité de la réponse cellulaire à une stimulation hormonale continue ou répétée. Cette diminution de la réponse cellulaire à toute stimulation ultérieure est appelée désensibilisation. Elle dépend de la concentration hormonale et de la durée d'exposition des cellules à l'hormone. Elle est en fait le résultat d'une combinaison de processus régulateurs qui se mettent en place tant au niveau du récepteur qu'aux différentes étapes intracellulaires de la transduction du signal hormonal impliquant les protéines G, l'adénylate cyclase, les phosphodiestérases, les PKA, les phosphatases et les mécanismes de transcription des gènes.

\section{Désensibilisation au niveau du récepteur FSH}

\section{Déplétion des récepteurs FSH}

La réponse des cellules de Sertoli à une stimulation par la FSH dépend en premier lieu du nombre de récepteurs disponibles à la surface cellulaire. In vivo, il existe une autorégulation par la FSH circulante du nombre 
de ses récepteurs à la surface de la cellule de Sertoli. Un effet positif de l'hormone sur le nombre de ses récepteurs est suggéré par le fait que le contenu testiculaire en récepteurs FSH est fortement augmenté au cours de la période où la FSH circulante est particulièrement élevée, c'est-à-dire entre le $15^{\circ}$ et le $40^{\circ}$ jour chez le rat (Ketelslegers et al, 1978). De plus, chez le rat (Ghosh et al, 1992) et la caille (Tsutsui et Ishii, 1980), l'hypophysectomie provoque une nette diminution du nombre de récepteurs FSH par testicule. Chez la caille hypophysectomisée, un traitement de remplacement par la FSH et la testostérone restaure le nombre de récepteurs testiculaires à FSH. En revanche, il existe aussi un effet négatif de la FSH sur ses propres récepteurs in vivo mais ceci à fortes concentrations d'hormone. Chez le rat adulte, l'injection intramusculaire (Gnanaprakasam et al, 1979) de FSH induit une diminution dans les 3 j du nombre des récepteurs FSH. Chez le rat immature, l'injection intratesticulaire de FSH $(25 \mu \mathrm{g})$ se traduit par une diminution des sites de liaison pour la $\mathrm{FSH}$ de $50 \%$ en $24 \mathrm{~h}$. Cette déplétion en récepteurs $\mathrm{FSH}$ est précédée par une diminution de la production d'AMPc par les cellules de Sertoli (O'Shaughnessy, 1980). Ces résultats suggèrent que, in vivo, la FSH à de faibles concentrations a un effet positif sur le nombre et le maintien de ses récepteurs et, à plus fortes concentrations, elle induit leur déplétion.

In vitro, le rétrocontrôle négatif de la FSH sur ses récepteurs a été retrouvé sur des cellules de Sertoli de rat en culture. En effet, $5 \mu \mathrm{g} / \mathrm{ml}$ de $\mathrm{FSH}$ provoquent une diminution maximale du nombre de récepteurs, qui peut se maintenir plusieurs jours. Cette perte des récepteurs s'accompagne d'une diminution de la réponse AMPc de la cellule (Francis et al, 1981). Strictement spécifique, ce phénomène n'affecte aucunement la réponse de la cellule à un autre activateur tel l'isoprotérénol, ni les différents effecteurs de la voie AMPc telles la protéine G ou l'adé- nylate cyclase (Jahnsen et al, 1982). Cette perte des récepteurs FSH en présence de l'hormone est liée aux processus d'internalisation du complexe hormone/récepteur et de dégradation ou recyclage du récepteur dans la cellule. L'hormone, après liaison à son récepteur membranaire, est internalisée avec celui-ci dans des vésicules d'endocytose qui migrent vers l'appareil de golgi et les lysosomes où l'hormone est dégradée (Shimizu et Kawashima, 1989). Le récepteur $\mathrm{FSH}$ est recyclé en partie vers la surface cellulaire, son accumulation au sein des lysosomes est donc progressive, ce qui conduit à plus ou moins long terme à sa dégradation. Chez le porc, la perte du nombre de récepteurs $\mathrm{FSH}$ induite par l'hormone dépend de la concentration hormonale $\left(E D_{50}=250 \mathrm{ng} / \mathrm{ml}\right)$ et du temps d'action $\left(t_{1 / 2}=14 \mathrm{~h}\right.$ ) (Saez et Jaillard, 1986). Cette déplétion en récepteurs FSH est plus importante en présence de monensine. La monensine est connue pour bloquer, d'une part, le recyclage des récepteurs par alcalinisation des endosomes et inhibition de la dissociation de l'hormone de son récepteur et, d'autre part, le transport vers la membrane de récepteurs néosynthétisés. Ainsi, le processus de «downregulation» serait dû à une accélération de l'internalisation du complexe hormone/récepteur. Mais le recyclage partiel des récepteurs atténue ce phénomène de déplétion.

De plus, la FSH peut aussi réguler le nombre de ses récepteurs en modulant leur synthèse par la cellule de Sertoli (Themmen et al, 1991). La FSH exerce un rétrocontrôle en diminuant la stabilité des ARNm de son récepteur, sans altérer la transcription du gène codant pour celui-ci. Cette chute post-transcriptionnelle du nombre d'ARNm entraînerait une diminution du nombre des récepteurs FSH néosynthétisés et exprimés à la surface cellulaire.

En résumé, la régulation par la $\mathrm{FSH}$ de ses récepteurs présente à court terme un cycle rapide d'internalisation et de retour 
vers la membrane et à long terme une perte nette du nombre des récepteurs par dégradation («downregulation») et diminution de leur synthèse.

\section{Découplage du récepteur FSH de sa voie d'activation}

Un autre type de désensibilisation, se développant à court terme, a été mis en évidence sur les cellules de Sertoli en culture stimulées par la FSH (Guillou et al, 1987) et sur cellules 293 exprimant le récepteur FSH humain recombinant (Sanchez-Yagüe et al, 1993). Cette réduction de la réponse à l'hormone est liée à une diminution de la production d'AMPc (Verhoeven et al, 1980 ; Conti et al, 1983b ; Verhoeven et Cailleau, 1986) consécutive à une baisse de l'activité de l'adénylate-cyclase sous l'action de la FSH (Jahnsen et al, 1982 ; Le Gac et al, 1985). Ceci serait dû au découplage du récepteur de la protéine $\mathrm{G}$ (Laurent-Cadoret et al, 1994a). Ce type de désensibilisation présente les caractéristiques suivantes :

- une grande sensibilité des cellules à ce processus. Cette désensibilisation est induite par de faibles doses de FSH $\left(10^{-11}\right.$ à $10^{-10}$ M) n'entraînant qu'une faible augmentation de l'AMPc pendant la préincubation ;

- la rapidité relative du processus, qui atteint son maximum en 1 à $4 \mathrm{~h}$;

- la réversibilité du processus. Une récupération de la sensibilité des cellules à la stimulation par FSH nécessite cependant 22 à $48 \mathrm{~h}$;

- l'inactivation importante mais partielle, environ de $60 \%$ à $80 \%$ d'inhibition, des réponses cellulaires comme l'activité adénylate cyclasique ou la production d'AMPC ou la sécrétion de l'activateur du plasminogène et de $17 \beta$ œstradiol ;

- le maintien du nombre de récepteurs FSH ;

- le maintien des propriétés fonctionnelles de la protéine Gs ou de la sous-unité cata- lytique de l'adénylate cyclase ainsi que de leur couplage.

Une étude approfondie de ce type de désensibilisation par découplage du récepteur FSH de la protéine $G$ nous a conduits à proposer l'existence de 2 formes de désensibilisation bien distinctes quant aux mécanismes moléculaires qui les régissent : l'une dite homo/hétérologue et l'autre homologue.

La désensibilisation homo/hétérologue implique la participation de kinases dépendantes des nucléotides. En effet, tout agent stimulateur de la voie AMPc/PKA (les analogues de l'AMPc ou l'isoprotérénol via les récepteurs $\beta$ adrénergiques) peut induire une désensibilisation notable des cellules de Sertoli à une stimulation ultérieure par la FSH, ceci quel que soit le type de PKA activée (Laurent-Cadoret et al, 1994a). De plus, les esters de phorbol, activateurs des PKC, peuvent provoquer une désensibilisation similaire (Monaco et Conti, 1987 ; Eikvar et al, 1993 ; Laurent-Cadoret et al, 1994a). Cette désensibilisation homo/hétérologue est insensible à la cycloheximide (Conti et al, 1983b ; Laurent-Cadoret et al, 1994b). Elle est observée pour des doses de FSH très faibles de $10^{-11} \mathrm{M}$ et des doses d'isoprotérénol ou d'analogues de l'AMPc peu ou non stimulantes des fonctions sertoliennes. En bloquant spécifiquement ces protéines kinases $\mathrm{A}$ et $\mathrm{C}$ par des inhibiteurs peptidiques, la composante homo/hétérologue de la désensibilisation est éliminée (Laurent-Cadoret et al, 1994b).

La suppression de cette première forme de désensibilisation dégage le profil d'une autre composante, cette fois-ci strictement spécifique de la FSH. Cette désensibilisation homologue est observée pour des doses de FSH supérieures à $10^{-10} \mathrm{M}$. La présence de cycloheximide abolit cette composante sans modifier la composante homo/hétérologue (Laurent-Cadoret et al, 1994b). Cette désensibilisation homologue ferait donc intervenir un facteur protéique synthétisé suite à l'action des doses désensibilisantes 
de FSH et qui participerait au découplage spécifique récepteur $\mathrm{FSH} /$ protéine $\mathrm{G}$.

Sur la base de ces données, le récepteur FSH serait le principal (ou peut être même l'unique) site de lésion de cette forme de désensibilisation. L'existence d'un tel découplage entre le récepteur FSH et sa voie d'activation aurait pour origine une modification du récepteur affectant ses propriétés de transduction du signal hormonal. Les données actuelles concernant ce type de désensibilisation pour le récepteur $\mathrm{FSH}$ ne permettent pas d'en préciser les mécanismes exacts. Cependant, il est intéressant de comparer ce processus de désensibilisation observé pour le récepteur FSH avec ceux mis en évidence sur d'autres récepteurs de la famille des récepteurs à 7 domaines transmembranaires couplés aux protéines $G$ (R7G) (Sprengel et al, 1990 ; Savarese et Fraser, 1992). Parmi ceux-ci nous pouvons citer notamment les récepteurs $\beta$-adrénergiques, muscariniques, rhodopsines, cholecystokiniques et lutéotropiques (Ligget et Raymond, 1993 ; Lee et Fraser, 1993 ; Hargrave et McDowell, 1992 ; Williams et Blevins, 1993 ; Segaloff et Ascoli, 1993 ; Hipkin et al, 1993). Ces récepteurs présentent la propriété d'être découplés de leur voie de transduction lors de la désensibilisation. L'étude la plus complète sur la désensibilisation par découplage d'un récepteur de la protéine Gs a été réalisée sur le récepteur $\beta 2$-adrénergique, mettant en évidence ses 2 composantes, l'une homo/hétérologue et l'autre homologue stricte.

La désensibilisation homo/hétérologue du récepteur $\beta 2$-adrénergique touche la réponse ultérieure à l'agoniste lui-même et celle à d'autres facteurs utilisant la voie de l'AMPc et est induite de manière non spécifique par ces différents agents. Elle fait intervenir la phosphorylation du récepteur par les protéines kinases dépendantes des nucléotides (PKA, PKC ou $\mathrm{Ca}^{2+} / \mathrm{Calmodu-}$ line protéine kinase) (Lohse et al, 1990a).
L'analyse de la structure du récepteur $\beta$ adrénergique a permis d'identifier ces sites potentiels de phosphorylation. La troisième boucle intracytoplasmique et l'extrémité carboxy-terminale du récepteur contiennent en effet chacune une séquence consensus RRSS- pour la phosphorylation par la PKA. Ces sites sont proches des régions du récepteur qui sont impliquées dans l'interaction avec la protéine Gs (Savarese et Fraser, 1992). Leur phosphorylation modifierait la distribution des charges dans ces zones structurées en hélices $\alpha$ et ainsi induirait, par altération de la conformation, le découplage récepteur/protéine Gs. La mutation de ces sites, sans bloquer la capacité de transduction du signal et d'internalisation du récepteur, entraîne en revanche une diminution de la capacité du récepteur à être phosphorylé et à subir la désensibilisation (Hausdorff et al, 1989). Cette phosphorylation catalysée principalement par les PKA est induite par de faibles concentrations en isoprotérénol (nanomolaire) (Hausdorff et al, 1989) et ses conséquences fonctionnelles se concrétisent par une diminution de la réponse AMPc de la cellule (Ligget et Raymond, 1993).

La désensibilisation homologue du récepteur $\beta 2$-adrénergique ne touche que la réponse à l'agoniste responsable de cette désensibilisation. Elle est aussi liée à la phosphorylation du récepteur mais par une protéine kinase indépendante de l'AMPc et reconnaissant le récepteur occupé par l'agoniste ; elle est dénommée « $\beta$-adrenergic receptor kinase» $\beta A R K$ (Lefkowitz, 1993). Elle est déclenchée à partir de concentrations en isoprotérénol de l'ordre du micromolaire (Hausdorff et al, 1989). Les sites potentiels de phosphorylation par cette kinase se situent dans l'extrémité carboxyterminale du récepteur, riche en sérines et thréonines. La mutation de ces sites (Hausdorff et al, 1989 ; Ligget et Raymond, 1993) altère la composante spécifique de désensibilisation. Les sites de phosphorylation par 
la $\beta$ ARK sont assez éloignés de zones d'interaction entre le récepteur et la protéine $G$, ce qui pourrait expliquer que ces phosphorylations n'induisent que partiellement le découplage. L'inactivation fonctionnelle du système nécessite l'intervention d'un facteur protéique cytosolique, de type arrestine, qui va se lier à la forme phosphorylée du récepteur et par encombrement stérique va compléter le découplage récepteur/protéine G (Lohse et al, 1990b ; Lefkowitz et al, 1992).

Ce processus de découplage par phosphorylation pourrait être applicable aux récepteurs des gonadotropines. En effet, Hipkin et al (1993) ont montré la phosphorylation in situ du récepteur $\mathrm{LH}$ via l'activation des PKA et PKC. Mais la phosphorylation du récepteur LH induit spécifiquement par l'hormone n'est que partiellement due à l'activation de ces voies impliquant les nucléotides. Ces auteurs postulent l'existence d'une kinase indépendante de ces seconds messagers et reconnaissant le récepteur occupé et activé par l'hormone. Récemment, Quintana et al (1994) ont montré que le récepteur FSH serait préférentiellement phosphorylé par la voie PKC stimulé par la FSH ; la phosphorylation du récepteur ayant pour conséquence un découplage du récepteur de la protéine $\mathrm{G}$.

Il apparaît donc que ces processus régulateurs mis en jeu au niveau du récepteur pourraient en fait s'appliquer de façon assez générale à cette famille de récepteurs à 7 domaines transmembranaires.

\section{Désensibilisation au niveau de la protéine $G$ ou de l'adénylate cyclase}

\section{Au niveau des protéines $\mathbf{G}$}

Parmi les divers mécanismes de désensibilisation de la réponse cellulaire, des modifications du taux de protéines Gi peuvent être une voie de rétrocontrôle de la transduction du signal hormonal (Reithmann et al, 1991).

Dans les cellules de Sertoli, il existe une protéine $\mathrm{Gi}$ qui exerce une inhibition constante sur l'activité de l'AC (Davenport et Heindel, 1987). L'inhibition de l'activité de la protéine Gi par la toxine pertussis augmente la capacité de la FSH à stimuler la production d'AMPc (Kangasniemi, 1993). Son activation, notamment par l'adénosine via les récepteurs $A 1$, peut inhiber la stimulation des cellules de Sertoli par la FSH chez le rat (Monaco et al, 1988b) et chez le hamster (Davenport et Heindel, 1987). De plus, $100 \mathrm{ng} / \mathrm{ml}$ de FSH sont capables de moduler l'expression des différentes formes de protéines Gi des cellules de Sertoli, diminuant en $6 \mathrm{~h}$ le taux des ARNm d' $\alpha \mathrm{i}-1$ et $\alpha \mathrm{i}-$ 2 et augmentant $\alpha \mathrm{i}-3$ (Loganzo et Flechert, 1992). L'expression de Gs n'est en revanche pas modifiée. Ces observations ne permettent pas actuellement de préciser si cette régulation des isotypes de la protéine $\mathrm{G}$ par la FSH peut modifier l'action ultérieure de l'hormone au sein de la cellule de Sertoli.

\section{Au niveau de l'adénylate cyclase}

L'activité de certaines $A C$, notamment les types 5 et 6 , peut être inhibée par phosphorylation par la PKA (Premont et al, 1992b). Dans les cellules où les AC de type 5 et 6 sont exprimées, une désensibilisation par tout agent activateur de la voie AMPc/PKA pourrait donc avoir lieu. Dans le testicule, les 3 types d'AC mises en évidence sont les formes 4,5 et 6 , mais leur répartition suivant le type cellulaire n'a pas été déterminée. Cependant, ce type de désensibilisation ne semble pas exister dans la cellule de Sertoli. En effet, dans les cellules de Sertoli désensibilisées par la $\mathrm{FSH}$, l'activité de l'AC stimulée par la forskoline ou le fluorure de sodium n'est pas modifiée (Jahnsen et al, 1982 ; Conti et al, 1983a ; Le Gac et al, 1985 ; Laurent-Cadoret et al, 1994a). 


\section{Désensibilisation en aval de la production d'AMPC}

\section{Par les phosphodiestérases}

La préincubation avec la FSH résulte en une diminution dose-dépendante de l'accumulation de l'AMPc non seulement dans le milieu mais aussi dans les cellules de Sertoli, au cours d'une seconde stimulation par l'hormone (Verhoeven et al, 1980). Cette inhibition est particulièrement intense, pouvant atteindre environ $80 \%$. Elle est liée d'une part à une diminution de sa synthèse, par diminution de l'activité adénylate cyclasique suite au découplage du récepteur de sa voie d'activation (phénomène décrit précédemment) et d'autre part à une augmentation de son catabolisme par activation de l'activité phosphodiestérasique au sein de la cellule. En effet, les phosphodiestérases (PDE), seule voie physiologique de dégradation par hydrolyse des nucléotides cycliques en nucléotides 5 ' correspondant, peuvent jouer un rôle important dans les processus de désensibilisation (Conti et al, 1991). Les cellules de Sertoli expriment conjointement les CaM-PDE et AMPc-PDE cytosoliques. Une modification élaborée de l'activité de ces différentes formes de PDE fait suite à l'activation de la voie de l'AMPC par la FSH. Les $\mathrm{Ca}^{2+/ C a M-P D E}$ sont les formes majoritaires des PDE présentes dans le cytosol des cellules de Sertoli de rat immature non stimulées. Lors de la stimulation par la $\mathrm{FSH}$, l'activité des $\mathrm{Ca}^{2+} / \mathrm{CaM}$ PDE est rapidement inhibée puis progressivement une augmentation de l'activité phosphodiestérasique apparaît dans les cellules, notable après $4 \mathrm{~h}$ de stimulation et qui est liée à l'accumulation des AMPC-PDE nouvellement synthétisées. Si le stimulus hormonal persiste, la forte activité phosphodiestérasique peut se maintenir au-delà de $24 \mathrm{~h}$. Cette induction retardée des AMPcPDE apparaît après le retour au niveau basal du taux d'AMPc. Les concentrations en AMPc sont alors au-dessous du $\mathrm{Km}$ de la PDE pour l'AMPc, impliquant que l'enzyme n'exprimera son activité catalytique que si les cellules sont à nouveau stimulées. $\mathrm{Ce}$ mécanisme de régulation servirait de rétrocontrôle négatif, permettant de diminuer plus rapidement la teneur intracellulaire en nucléotides cycliques. L'induction à long terme des AMPc-PDE par une première stimulation par la FSH est un facteur majeur de contrôle de la réponse des cellules de Sertoli et contribue à une baisse ou même à une suppression de sa réponse ultérieure à la FSH (Conti et al, 1986). Elle est liée à une néosynthèse de molécules et peut être induite par tout agent activateur de la voie AMPc tels le db-AMPc mais aussi, dans une moindre mesure, l'isoprotérénol. C'est donc une forme hétérologue de désensibilisation nécessitant de plus une synthèse protéique.

\section{Par l'inhibiteur des PKA}

Cet inhibiteur des PKA (PKI) a été mis en évidence dans différents tissus, incluant le cœur, le cerveau, le muscle et le testicule. Cet inhibiteur est un peptide de petite taille (8 kDa) qui, comme la sous-unité régulatrice de la PKA, agit comme pseudo-substrat en se liant au site actif de la sous-unité catalytique de la PKA. Chez le rat, 2 formes de $\mathrm{PKI}, \mathrm{PKI} \alpha$ et $\mathrm{PKI} \beta$, ont été identifiées dans le testicule (Van Patten et al, 1992). Il existe une expression différentielle de ces 2 formes au cours du développement : l'expression de PKI $\alpha$ décroît de la naissance jusqu'à l'âge de $20 \mathrm{j}$, puis la forme PKI $\beta$ apparaît et son expression augmente jusqu'à l'âge adulte.

L'activité de cet inhibiteur est sous le contrôle spécifique de la FSH (Tash et al, 1979). En effet, chez le rat, l'hypophysectomie entraîne une diminution de l'activité $\mathrm{PKI}$, qui peut être rétablie par traitement de l'animal avec de la FSH. L'injection de la FSH est suivie d'une augmentation de l'ac- 
tivité $\mathrm{PKI}$ en $12 \mathrm{~h}$ qui continue lentement si de nouvelles injections de FSH sont effectuées. Une néosynthèse de l'inhibiteur est à l'origine de cette augmentation d'activité. De plus, la régulation par la FSH de l'activité PKI dépend de l'âge de l'animal : un pic d'activité de cet inhibiteur sous stimulation FSH est observé chez des rats immatures âgés de 12 à $19 \mathrm{j}$, la faible activité résiduelle observée à l'âge de 20 j décroît jusqu'à l'âge adulte de l'animal.

In vitro, la localisation intracellulaire du PKI a été déterminée à l'aide d'anticorps au niveau des microtubules (Tash et al, 1980). L'activité PKI est stimulée par la FSH $\left(E D_{50}=20 \mathrm{ng} / \mathrm{ml}\right)$ significativement dès $4 \mathrm{~h}$ puis se développe sur $24 \mathrm{~h}$. De même, la dépendance de cette stimulation vis-à-vis de l'âge de l'animal dont proviennent les cellules est toujours observée (Tash et al, 1981). Elle explique en partie le fait que les cellules de Sertoli perdent leur faculté de réponse à la stimulation $\mathrm{FSH}$ au cours de la maturation du testicule.

Ainsi cet inhibiteur des PKA, dont l'activité est augmentée par la FSH en quelques heures par néosynthèse de molécules, est donc capable en bloquant l'activité de la PKA de désensibiliser les cellules de Sertoli lors de stimulations continues ou répétées par la FSH. II peut être stimulé par tout agent activateur de la voie de l'AMPc et notamment l'isoprotérénol. C'est donc une forme hétérologue de désensibilisation nécessitant de plus une synthèse protéique.

\section{Par les phosphatases}

Du fait de leurs facultés à inverser l'action des PKA, les phosphatases sont des acteurs potentiels de désensibilisation de la réponse cellulaire lorsqu'elle est médiée par la voie AMPc mais elles pourraient aussi, théoriquement, "résensibiliser»le récepteur FSH phosphorylé. L'implication des phosphatases dans la modulation de l'action de la FSH dans le testicule n'a cependant pas été étudiée. Les seules données disponibles sont l'identification des 4 isozymes majeurs de ces sérine/thréonine phosphatases dans le testicule dénommées PP-1, PP-2A, PP-2B (calcineurine), et PP2C (Cohen, 1989).

\section{Au niveau transcriptionnel}

Dans le cas des gènes dont la transcription est contrôlée par l'AMPc, il a été observé qu'une stimulation de courte durée provoque une augmentation de la transcription suivie d'une inhibition de celle-ci (Hagiwara et al, 1992). Ce phénomène a été observé dans la cellule de Sertoli sous stimulation FSH. En effet, la FSH provoque une augmentation de la transcription du gène de la transferrine en $2 \mathrm{~h}$ puis une diminution de la transcription de ce gène (Suire, communication personnelle). Ce phénomène peut être induit aussi par le db-AMPc.

\section{CONCLUSION}

La réponse des cellules de Sertoli à l'action de la FSH est continuellement ajustée en fonction de l'environnement extracellulaire comme intracellulaire. Notamment, les autres cellules testiculaires par la sécrétion de facteurs paracrines ou les modifications qualitatives et quantitatives des acteurs des voies de transduction du signal dans la cellule de Sertoli ainsi que des niveaux circulants de FSH au cours du développement vont moduler la physiologie sertolienne (pour revue, voir Russel et Griswold, 1993). Les mécanismes à l'origine de cette adaptation cellulaire sont complexes. Parmi ceux-ci, les processus de découplage du récepteur du complexe récepteur $\mathrm{FSH} /$ protéine Gs/AC à court terme puis l'augmentation de l'activité phosphodiestérasique et de l'inhibiteur des PKA ainsi que la déplétion des récepteurs à plus long terme peuvent se compléter pour engendrer une désensibilisation des 
cellules de Sertoli. II se forme ainsi un savant équilibre entre stimulation et désensibilisation dont le rôle serait d'une part de protéger les voies de transmission et d'intégration du signal hormonal lors d'une éventuelle augmentation pathologique de la concentration hormonale et d'autre part de réguler positivement comme négativement la sensibilité des cellules à l'action hormonale.

\section{RÉFÉRENCES}

Blum WFP, Gupta (1985) Heterogeneity of rat FSH by chromatofocusing: studies on serum $\mathrm{FSH}$, hormone released in vitro and metabolic ciearance rates of its various forms. J Endocr 105, 29-37

Bortolussi M, Zanchetta R, Belvedere P, Colombo L (1990) Sertoli and Leydig cell numbers and gonadotropin receptors in rat testis from birth to puberty. Cell Tissues Res 260, 185-191

Braun T, Schofield PR, Sprengel R (1991) Amino-terminal leucine-rich repeats in gonadotropin receptors determine hormone selectivity. Embo $J 10$, 18851890

Cohen $P$ (1989) The structure and regulation of protein phosphatases. Ann Rev Biochem 58, 453-508

Combarnous $Y$ (1992) Molecular basis of the specificity of binding of glycoprotein hormones to their receptors. Endocrine Reviews 13, 670-691

Conti M, Toscano MV, Petrelli L, Geremia R, Stefanini M (1983a) Follicle-stimulating hormone regulates in vivo testicular phosphodiesterase. Mol Cell Endocrinol 29, 79-89

Conti M, Toscano MV, Petrelli L, Geremia R, Stefanini M (1983b) Involvement of phosphodiesterase in refractoriness of the Sertoli cell. Endocrinology 113, 18451853

Conti M, Monaco L, Petrelli L, Geremia R, Stefanini M (1986) Effect of phosphodiesterase inhibitors on Sertoli cell refractoriness: reversal of the impaired androgen aromatization. Endocrinology 118, 901-908

Conti M, Jin SLC, Monaco L, Repaske DR, Swinnen JV (1991) Hormonal regulation of cyclic nucleotide phosphodiesterases. Endocrine Reviews 12, 218-234

Dattatreyamurty B, Reichert LE (1992) A synthetic peptide corresponding to amino acids 9-30 of the extracellular domain of the follitropin (FSH) receptor specifically binds FSH. Mol Cell Endocrino/ 87, 9-17

Dattatreyamurty B, Figgs LW, Reichert LE (1987) Physical and functional association of follitropin receptors with cholera toxin-sensitive guanine nucleotide-binding protein. J Biol Chem 262, 11737-11745
Davenport CW, Heindel JJ (1987) Tonic inhibition of adenylate cyclase in cultured hamster Sertoli cells. $J$ Androl 8, 314-318

Dohler KD, Wuttke W (1975) Changes with age in serum levels gonadotropins, prolactin and gonadal steroids in prepubertal male and female rats. Endocrinology 97, 898-907

Dym M, Lamsam-Casalotti S, Meng-Chum J, Kleinman HK, Papadopoulos V (1991) Basement membrane increases $\mathrm{G}$-protein levels and follicle-stimulating hormone responsiveness of Sertoli cell adenylyl cyclase activity. Endocrinology 128, 1167-1176

Eikvar L, Tasken KA, Eskild W, Hansson V (1993) Protein kinase $C$ activation and positive and negative agonist regulation of $3^{\prime}, 5^{\prime}$-cyclic adenosine monophosphate levels in cultured rat Sertoli cells. Acta Endocrinol 128, 568-572

Eskola V, Nikula H, Huhtaniemi I (1993) Age-related variation of follicle-stimulating hormone-stimulated cAMP production, protein kinase $\mathrm{C}$ activity and their interactions in the rat testis. Mol Cell Endocrinol 93, 143-148

Farese RV (1984) Phospholipids as intermediates in hormone action. Mol Cell Endocrinol 35, 1-14

Fletcher PW, Reichert LE (1986) Guanine triphosphatebinding site regulation by follicle-stimulating hormone and guanine diphosphate in membranes from immature rat Sertoli cells. Endocrinology 119, 2221. 2226

Francis GL, Brown TJ, Bercu BB (1981) Control of Sertoli cell response to $\mathrm{FSH}$ : regulation by homologous hormone exposure. Biol Reprod 24, 955-961

Gao B, Gilman AG (1991) Cloning and expression of a widely distributed (type IV) adenylyl cyclase. Proc Natl Acad Sci USA 88, 10178-10182

Geremia R, Rossi P, Pezzotti R, Conti M (1982) Cyclic nucleotide phosphodiesterase in developing rat testis. Identification of somatic and germ-cell forms. Mol Cell Endocrinol 28, 37-53

Ghosh S, Bartke A, Grasso P, Reichert LE, Russell LD (1992) Structural manifestations of the rat Sertoli cell to hypophysectomy: a correlative morphometric and endocrine study. Endocrinology 131, 485-497

Gnanaprakasam MS, Chen CJH, Sutherland JG, Bhalla VK (1979) Receptor depletion and replenishment process: in vivo regulation of gonadotropin receptors by luteinizing hormone, follicle stimulating hormone and ethanol in rat testis. Biol Reprod 20, 9911000

Gorczynska E, Handelsman DJ (1991) The role of calcium in follicle-stimulating hormone signal transduction in Sertoli cells. J Biol Chem 266, 2373923744

Grasso P, Reichert LE (1990) Follicle-stimulating hormone receptor-mediated uptake of ${ }^{45} \mathrm{Ca}^{2+}$ by cultured rat Sertoli cells does not require activation of cholera toxin- or pertussis toxin-sensitive guanine 
nucleotide binding proteins or adenylate cyclase. Endocrinology 127, 949-956

Grasso P, Reichert LE (1993) Induction of calcium transport into cultured rat Sertoli cells and liposomes by follicle-stimulating hormone. Recent Prog Hormone Res 48, 517-521

Griswold MD (1993) Actions of FSH on mammalian Sertoli cells. In: Sertoli cell (LD Russel, MD Griswold, eds), Cache River Press, Cleawater, FL, États-Unis, 494-508

Guillou F, Martinat N, Combarnous Y (1987) Homologous desensitization of rat Sertoli cells by non-stimulating concentrations of follicle-stimulating hormone. Biol Cell 59, 227-232

Hagiwara M, Alberts A, Brindle $M$ et al (1992) Transcriptional attenuation cAMP induction requires PP-1mediated dephosphorylation of CREB. Cell 70, 105113

Hargrave PA, Mc Dowell (1992) Rhodopsin and phototransduction: a model system for $\mathrm{G}$ protein-linked receptors. FASEB J 6, 2323-2331

Hausdorf WP, Bouvier M, O'Dowd BF, Irons GP, Caron MG, Lefkowitz RJ (1989) Phosphorylation sites on 2 domains of the $\beta 2$-adrenergic receptor are involved in distinct pathways of receptor desensitization. $J$ Biol Chem 264, 12657-12665

Heckert LL, Griswold MD (1992) Expression of the FSH receptor in the testis. Recent Prog Horm Res 48, 61-77

Heckert LL, Daley IJ, Griswold MD (1992) Structural organization of the follicle-stimulating hormone receptor gene. Mol Endocrinol 6, 70-80

Hipkin RW, Sanchez-Yagüe J, Ascoli M (1993) Agonistinduced phosphorylation of the luteinizing hormone/chorionic gonadotropin receptor expressed in a stably transfected cell line. Mol Endocrinol 7, 823832

Hugh H, Sarre TF (1993) Protein kinase C isoenzymes: divergence in signal transduction? Biochem J 291 , 329-343

Ireland ME, Rosenblum BB, Welsh MJ (1986) Twodimensional gel analysis of Sertoli cell protein phosphorylation: effect of short-term exposure to folliclestimulating hormone. Endocrinology 118, 526-532

lyengar R (1993) Molecular and functional diversity of mammalian Gs-stimulated adenylyl cyclases. FASEB $J 7,768-775$

Jahnsen T, Verhoeven G, Purvis K, Cusan L, Hansson $V$ (1982) Desensitization of FSH-responsive adenyl cyclase in cultured immature Sertoli cells by homologous hormone. Androl Arch 8, 205-211

Joffre M, Roche A (1988) Follicle stimulating hormone induces hyperpolarization of immature rat Sertoli cells in monolayer culture. J Physiol 400, 481-499

Kangasniemi (1993) Effects of adenosine analog PIA on FSH-stimulated cyclic AMP production in rat semi- neferous epithelium. Mol Cell Endocrinol 96, 141146

Kangasniemi M, Kaipia A, Toppari J, Perheentupa A, Huhtaniemi I, Parvinen M (1990a) Cellular regulation of follicle-stimulating hormone (FSH) binding in rat seminiferous tubules. J Androl 11, 336-343

Kangasniemi M, Kaipia A, Mali P, Toppari J, Huhtaniemi I. Parvinen M (1990b) Modulation of basal and FSHdependent cyclic AMP production in rat seminiferous tubules staged by an improved transillumination technique. Anat Rec 227, 62-76

Kelton CA, Cheng SVY, Nugent NP et al (1992) The cloning of the human follicle stimulating receptor and its expression in $\mathrm{COS}-7, \mathrm{CHO}$, and $\mathrm{Y}-1$ cells. $\mathrm{MO}$ Cell Endocrinol 89, 141-151

Ketelslegers JM, Hetzel WD, Sherins RJ, Catt KJ (1978) Developmental changes in testicular gonadotropin receptors: plasma gonadotropins and plasma testosterone in the rat. Endocrinology 103, 212-222

Knutsen HK, Tasken KA, Eskild W, Janhsen T, Hansson $V$ (1991) Adenosine 3',5'-monophosphate-dependent stabilization of messenger ribonucleic acids (mRNAs) for protein kinase-A (PKA) subunits in rat Sertoli cells: rapid degradation of mRNAs for PKA subunits is dependent on ongoing RNA and protein synthesis. Endocrinology 129, 2496-2502

Lamsam-Casalotti S, Onoda M, Papadopoulos V, Dym $M$ (1993) Developmental expression of GTP-binding proteins in rat testes. $J$ Reprod Fertility 99 487-495

Landmark BF, Fauske B, Eskild W et al (1991) Identification, characterization, and hormonal regulation of 3',5'-cyclic adenosine monophosphate-dependent protein kinases in rat Sertoli celis. Endocrinology $129,2345-2354$

Landmark BF, Oyen O, Skalhegg B, Fauske B, Jahnsen $T$, Hansson V (1993) Cellular location and agedependent changes of CAMP-dependent protein kinase in rat testis. $J$ Reprod Fert 99, 323-334

Laurent-Cadoret V, Guillou F, Combarnous $Y$ (1993) Involvement of cyclic adenosine monophosphatedependent protein kinase isozymes in tissue plasminogen activator secretion by rat Sertoli cells stimulated with follicle-stimulating hormone. Acta Endocrinol 128, 555-562

Laurent-Cadoret V, Guillou F, Combarnous Y (1994a) Heterologous and homologous desensitizations of the plasminogen activator response of rat Sertoli cells by FSH and isoproterenol. Endocrine 2, 805812

Laurent-Cadoret V, Guillou F, Combarnous Y (1994b) Protein kinases and protein synthesis are involved in desensitization of the plasminogen activator response of rat Sertoli cells by follicle-stimulating hormone. FEBS Letters 352, 19-23

Lee NH, Fraser C (1993) Cross-talk between ml muscarinic acetylcholine and $\beta 2$-adrenergic receptor. $J$ Biol Chem 268, 7949-7957 
Le Gac F, Attramadal H, Jahnsen T, Hansson V (1985) Studies on the mechanism of follicle-stimulating hormone-induced desensitization of Sertoll cell adenylyl cyclase in vitro. Biol Reprod 32, 916-924

Lefkowitz RJ (1993) G protein-coupled receptor kinases. Cell 74, 409-412

Lefkowitz RJ, Hausdorff WP, Caron MG (1990) Role of phosphorylation in desensitization of the $\beta$-adrenoreceptor. Trends in Pharmacol Sci 11, 190-194

Lefkowitz RJ, Inglese J, Koch WJ, Pitcher J, Attradamal H, Caron MG (1992) G-protein-coupled receptors: regulatory role of receptor kinase and arrestin proteins. 'Receptor regulation', Cold Spring Harbor, Symposia on Quantitative Biology, vol LVII, 127-133

Ligget SB, Raymond JR (1993) Pharmacology and molecular biology of adrenergic receptors. Baillere's Clinical Endocrinology and Metabolism Vol 7, $\mathrm{n}^{\circ}$ 2, 279-306

Loganzo F, Fletcher PW (1992) Follicle-stimulating hormone increases guanine nucleotide-binding regulatory protein subunit $\alpha i-3$ mRNA but decreases $\alpha i-1$ and oi-2 mRNA in Sertoli cells. Mol Endocrinol 6, 1259-1267

Lohse MJ, Benovic JL, Caron MG, Lefkowitz RJ (1990a) Multiple pathways of rapid $\beta 2$-adrenergic receptor desensitization. J Biol Chem 265, 3202-3209

Lohse MJ, Benovic JL, Codina J, Caron MG, Lefkowitz RJ (1990b) $\beta$-Arrestin: a protein that regulated $\beta 2$ adrenergic receptor function. Science 248,1547 1549

Means AR, MacDougall E, Soderling TR, Corbin JD (1974) Testicular adenosine 3':5'-monophosphatedependent protein kinase. Regulation by follicle-stimulating hormone. J Biol Chem 49, 1231-1238

Misrahi M, Hai MTV, Ghinea N et al (1993) Molecular and Cellular Biology of Gonadotropin Receptors. The Ovary. Raven Press, New York, 57-88

Monaco L, Conti M (1987) Inhibition by phorbol esters and other tumor promoters of the response of the Sertoli cell to FSH: evidence for dual site of action. Mol Cel Endocrinol 49, 227-236

Monaco L, Adamo S, Conti M (1988a) Follicle-stimulating hormone modulation of phosphoinositide turnover in the immatture rat Sertoli cell in culture. Endocrinology 123, 2032-2039

Monaco L, Adamo S, Conti M (1988b) Adenosine inhibition of the hormonal response in the Sertoli cell is reversed by pertussis toxin. Endocrinology 122 , 2692-2698

Nikula H, Naor Z, Parvinen M, Huhtaniemi I (1987) Distribution and activation of protein kinase $C$ in the rat testis tissue. Mol Cell Endocrinol 49, 39-49

O'Shaughnessy PJ (1980) FSH receptor autoregulation and cyclic AMP production in the immature rat testis. Biol Reprod 23, 810-814

Padmanabhan V, Sairam MR, Hassing JM, Brown MB, Ridings JWW, Beitins IZ (1991) Follicle-stimulating hormone signal transduction: role of carbohydrate in aromatase induction in immature rat Sertoli cells. Moll Cell Endocrinol 79, 119-128

Paulssen RH, Paulssen EJ, Gordeladze JO, Hansson V, Haugen TB (1991) Cell-specific expression of guanine nucleotide-binding proteins in rat testicular cells. Biol Reprod 45, 566-571

Pelosin JM, Ricouart A, Sergheraert C, Benahmed M, Chambaz EM (1991) Expression of protein kinase C isoforms in various steroidogenic cell types. Mol Cell Endocrinol 75, 149-155

Premont RT, Chen J, Ma HW, Ponnapalli M, lyengar R (1992a) Two members of a widely expressed subfamily of hormone-stimulated adenylyl cyclases. Proc Natl Acad Sci USA 89, 9809-9813

Premont RT, Jacobowitz O, lyengar R (1992b) Lowered responsiveness of the catalyst of adenylyl cyclase to stimulation by $\mathrm{Gs}$ in heterologous desensitization: a role for adenosine 3',5'-monophosphate-dependent phosphorylation. Endocrinology 131, 2774-2784

Quintana J, Hipkin RW, Sanchez-Yagüe J, Ascoli M (1994) Follitropin (FSH) and phorbol ester stimulate the phosphorylation of the FSH receptor in intact cells. J Biol Chem 269, 8772-8779

Quirk SM, Reichert LE (1988) Regulation of the phosphoinositide pathway in cultured Sertoli celis from immature rats: effects of follicle-stimulating hormone and fluoride. Endocrinology 123, 230-237

Reichert LE, JR, Dattatreyamurty B (1989) The folliclestimulating hormone (FSH) receptor in testis: interaction with $\mathrm{FSH}$, mechanism of signal transduction, and properties of the purified receptor. Biol Reprod $40,13-26$

Reithmann C, Gierschick P, Werdan K, Jakobs KH (1991) Role of inhibitory $G$ protein $\alpha$-subunits in adenylyl cyclase desensitization. Mol Cell Endocrinol 82, C215-C221

Rousseau-Merck MF, Atger M, Loosfelt H, Milgrom E, Berger R (1993) The chromosomal localization of the human follicle-stimulating hormone gene (FSHR) on $2 \mathrm{p} 21-\mathrm{p} 16$ is similar to that of the luteinizing hormone receptor gene. Genomics 15, 222-224

Russel LD, Griswold MD (1993) Sertoli cell. In: "The Sertoli cell" (LD Russel, MD Griswold, eds), Cache River Press, Clearwater, FL, États-Unis, 1-747

Saez JM, Jaillard C (1986) Processing of follitropin and its receptor by cultured pig Sertoli cells. Eur J Biochem 158, 91-97

Sanchez-Yagüe J, Hipkin RW, Ascoli M (1993) Biochemical properties of the agonist-induced desensitization of the follicle-stimulating hormone and luteinizing hormone/chorionic gonadotropin-responsive adenylyl cyclase in cells expressing the recombinant gonadotropin receptors. Endocrinology 132 1007-1016

Santa Coloma TA, Grasso P, Reichert LE (1992) Synthetic human folicle-stimulating hormone- $\beta-(1-15)$ 
peptide-amide binds $\mathrm{Ca}^{2+}$ and possesses sequence similarity to calcium binding sites of calmodulin. Endocrinology 130, 1103-1107

Savarese TM, Fraser CM (1992) In vitro mutagenesis and the search for structure-function relationship among $\mathrm{G}$ protein-coupled receptors. Biochem J 283, 1-19

Segaloff DL, Ascoli M (1993) The lutropin/choriogonadotropin receptor... 4 years later. Endocrine reviews $14,324-347$

Shibata EF, Matsuda JJ, Volk KA, Collison KA, Segaloff DL (1992) Evidence that the FSH receptor itself is not a calcium channel. Endocrinology 131, 979-981

Shimizu A, Kawashima S (1989) Kinetic study of internalization and degradation of 131/-labeled follicle-stimulating hormone in mouse Sertoli cells and its relevance to other systems. J Biol Chem 264, 13632-13638

Simon MI, Strathmann MP, Gautam N (1991) Diversity of $\mathrm{G}$ proteins in signal transduction. Science 252 , 802-808

Sprengel R, Braun T, Nikolics K, Segaloff DL, Seeburg $\mathrm{PH}$ (1990) The testicular receptor for follicle stimulating hormone: structure and functional expression of cloned cDNA. Mol Endocrinol 4, 525-530

Strosberg AD (1991) Structure/function relationship of proteins belonging to the family of receptors coupled to GTP-binding proteins. Eur J Biochem 196, 1-10

Swinnen JV, Joseph DR, Conti M (1989) Molecular cloning of rat homologues of the Drosophila melanogaster dunce CAMP phosphodiesterase: Evidence for a family of genes. Proc Natl Acad Sci USA 86, 5325-5329

Swinnen JV, Tsikalas KE, Conti M (1991) Properties and hormonal regulation of 2 structurally related cAMP phosphodiesterases from the rat Sertoli cell. J Biol Chem 266, 18370-18377

Tash JS, Dedman JR, Means AR (1979) Protein kinase inhibitor in Sertoli cell-enriched rat testis. J Biol Chem 254, 1241-1247

Tash JS, Welsh MJ, Means AR (1980) Protein inhibitor of CAMP-dependent protein kinase: production and characterization of antibodies and intracellular localization. Cell 21, 57-65

Tash JS, Welsh MJ, Means AR (1981) Regulation of protein kinase inhibitor by follicle-stimulating hormone in Sertoli cells in vitro. Endocrinology 108, 427-434

Taylor SS, Knighton DR, Zheng J, Ten Eyck LF, Sowadski JM (1992) Structural framework for the protein kinase family. Annu Rev Cell Biol 8, 429-462
Themmen APN, Blok LJ, Post M et al (1991) Follitropin receptor down-regulation involves a CAMP-dependent post-transcriptional decrease of receptor mRNA expression. Mol Cell Endocrinol 78, R7-R13

Tsutsui K, Ishii S (1980) Hormonal regulation of folliclestimulating hormone receptors in the testes of Japanese quail. $J$ Endocrinol 85, 511-518

Van Patten SM, Howard P, Walsh DA, Maurer RA (1992) The $\alpha$ - and $\beta$-isoforms of the inhibitor protein of the $3^{\prime}, 5$ '-cyclic adenosine monophosphate-dependent protein kinase: characteristics and tissue- and developmental-specific expression. Mol Endocrinol 6, 2114-2122

Verhoeven G, Cailleau J (1986) Desensitization of Sertoli cell-enriched cultures by $\mathrm{FSH}$, L-isoproterenol and glucagon. Influence on subsequent stimulation of 17 $\beta$-estradiol production. Mol Cell Endocrinol 20 , 113-126

Verhoeven G, Cailleau J, De Moor P (1980) Desensitization of cultured rat Sertoli cells by follicle-stimulating hormone and by L-isoproterenol. Mol Cell Endocrinol 20, 113-126

Verhoeven G, Cailleau J, De Moor P (1981) Hormonal control of phosphodiesterase activity in cultured rat Sertoli cells. Mol Cell Endocrinol 24, 41-51

Waeber G, Meyer TE, Lesieur M, Hermann HL, Gerard N, Habener JF (1991) Developmental stage-specific expression of cyclic adenosine 3',5"monophosphate response element-binding protein CREB during spermatogenesis involves alternative exon splicing. $\mathrm{Mol}$ Endocrinol 5, 1418-1430

Wassermann GF, Bloch LM, Grillo ML, Silva FRMB, Loss ES, McConnell LL (1992) Electrophysiological changes of Sertoli cells produced by the acute administration of amino acid and FSH. Horm Metab Res 24, 326-328

Wilden U, Kühn H (1982) Light-dependent phosphorylation of rhodopsin: number of phosphorylation sites. Biochem 21, 3014-3022

Williams JA, Blevins GT (1993) Cholecystokinin and regulation of pancreatic acinar cell function. Physiological Reviews 73, 701-723

Yamey TA, Sairam MR, Khan $H$, Ravindranath N, Payne S, Seidah NG (1993) Molecular cloning and expression of the ovine testicular follicle-stimulating hormone receptor. Mol Cell Endocrinol 93, 219-226

Zhang SB, Dattatreyamurty B, Reichert LE (1991) Differential roles of high and low affinity guanosine $5^{\prime}-$ triphosphate binding sites in the regulation of follicle-stimulating binding to receptor and signal transduction in bovine calf testis membranes. Endocrinology $128,295-302$ 